Published as: Neutens, T., Delafontaine, M., Scott, D.M. \& De Maeyer, P. (2012), A GIS-based method to identify spatiotemporal gaps in public service delivery. Applied Geography, vol. 32 (2), p. 253-264.

\title{
A GIS-based method to identify spatiotemporal gaps in public service delivery
}

[Paper submitted for possible publication in Applied Geography] 


\begin{abstract}
The focus of methodological approaches to identify (public) service deprivation has been predominantly on the shortcomings in the spatial coverage of the transportation system and the urban opportunity landscape. Accessibility is thereby generally modeled as a static concept with little - if any - account for temporal variations in services and transportation provision across the diurnal cycle and week, such as those resulting from opening hours and congestion effects. This paper suggests the use of time-specific measures of service accessibility and demand. The measures are integrated in a GIS-based multi-criteria analysis with the aim to detect spatiotemporal variations in service deprivation. The applicability of the method has been illustrated in a case study about the planning of a mobile government office bus in the city of Ghent (Belgium). It has been shown that the suitability of alternative stop locations for the bus depends on the time interval during which it will be operated.
\end{abstract}

\title{
Keywords
}

Accessibility; public services; GIS; multi-criteria analysis 


\section{Introduction}

In recent years, the causal relationship between transportation disadvantages and social exclusion has been brought to the forefront of the transportation policy debate. Central to this debate is that inadequacies in transportation provision may exclude certain population segments from fully participating in the 'normal' range of activities of daily life such as education, employment, health care, and various social and leisure pursuits (Lucas, 2006; Preston and Raje, 2007). In particular, there has been a growing concern that the non-uniform spatial distribution of the transportation infrastructure and the arrangement of land-uses fosters social exclusion as it inevitably favors particular socio-spatial population groups above others (Scott and Horner, 2008).

In recognition of this concern, a burgeoning strand of literature has sought to clarify empirically the link between transportation provision and activity participation from the perspective of population groups who are known to be at risk of social exclusion, including the elderly, those living on low incomes (e.g. Lucas et al., 2009), women (e.g. Turner and Grieco, 2000), children (e.g. Casas et al., 2009), people with disabilities (e.g. Church and Marston, 2003) and certain minority ethnic groups (e.g. Comber et al., 2008). Using a wide range of accessibility measures, several studies have examined the spatial mismatches between the home location of vulnerable population groups and key urban services. For example, Langford and Higgs (2010) have examined the extent to which rural communities in Wales have been impacted disproportionately - relative to urban communities - by post office closures in terms of the extra distances involved in travelling to the nearest outlet. Omer (2006), for his part, has used detailed geo-referenced socio-demographic census data to assess the accessibility to urban parks for different ethnic and income groups in the city of Tel Aviv (Israel) on the basis of park area within Euclidian buffers surrounding residential locations. Spatial equity of public service delivery has been studied by Talen and Anselin (1998) who have made a comparative analysis of different accessibility measures in the empirical context of public playgrounds in Tulsa, Oklahoma (US). Their study has been furthered in Tsou et al. (2005), which provides a GIS based analysis of the spatial patterns of the level of various types of public services in RenDe (Taiwan) using an integrated equity index.

As the above studies illustrate, accessibility analysis may facilitate a better understanding of transportation-engendered issues of social exclusion as it offers a powerful instrument to designate underserved neighborhoods. However, while topological and spatial barriers to access have aroused a great deal of academic attention, the role of temporal constraints on activity participation has been much less well understood and pronounced in empirical research. Traditionally, access to opportunities is deemed static with little - if any - account for temporal variations in service and transportation provision across the diurnal cycle and week, such as those resulting from opening hours and congestion effects. Furthermore, more often than not, no attention is paid to the fact that activities are spatially and temporally linked in chains. A significant exception to these shortcomings includes the line of research that has focused on the development of person-based measures of accessibility based on time geography (e.g. Casas, 2007; Miller, 2007; Kwan and Weber, 2008; Neutens et al., 2010b; Neutens et al., 2010c; Delafontaine et al., 2011). These measures are insightful to reveal individual differences in accessibility in a very detailed manner, but do not allow exploring generalizable spatial patterns of service 
deprivation at the city level. Furthermore, they require the implementation of dedicated algorithms and individual-level activity-travel data (Neutens et al., 2011).

This paper seeks to measure accessibility to services at a particular location per time window. Multiple accessibility measures are employed in a method that enables the demarcation of underserved areas in space-time. The proposed method consists of a multi-criteria evaluation of spatiotemporal measures of service accessibility on the one hand, and spatiotemporal measures of demand for services, on the other. The measures of accessibility and demand are calculated using four different sources of data: (i) transportation network data, (ii) information about the location and operating hours of individual services, (iii) census data per ward, and (iv) origin-destination (OD) output from a macroscopic traffic simulation model. To illustrate our method, an empirical case study is elaborated that aims to examine the suitability of stops for a mobile government office bus that will be operated by local authorities in the city of Ghent (Belgium).

\section{Method}

\subsection{Spatiotemporal accessibility of services}

Four different time-dependent accessibility measures are used in this study to express the degree to which a particular location or zone is served during a time window. The reason behind the deployment of multiple measures is based on previous findings (Kwan, 1998; Neutens et al., 2010a) that have highlighted the significant implications of the choice of measure for the assessment of equity of service distribution. Each of the measures employed generates insight into different dimensions of access to service supply. These aspects include the ability to reach a service, the minimum required travel time, the number of alternative services to choose from, and the time that can possibly be spent at a service. Prior to specifying these measures formally, we set out the conditions that must be fulfilled in order for a location to be served.

Let $z$ denote the zone for which accessibility to service facilities $f$ is to be determined, and $T(z, f)$ and $T(f, z)$ denote the travel time from $z$ to $f$ and from $f$ to $z$, respectively. Given a set $F$ of service facilities $f$ with a set $R_{f}$ of opening hour intervals $\left[t_{f, s}, t_{f, e}\right]$, and a time window starting from $t_{1}$ to $t_{2}$ during which the accessibility to $F$ at location $z$ is evaluated, there may exist a service facility $f \epsilon F$ and an associated opening hour interval $\left[t_{f, s}, t_{f, e}\right]$ in $R_{f}$ for which the following conditions hold:

$$
\begin{aligned}
& c_{1}: t_{1}+T(z, f)<t_{f, e} \\
& c_{2}: \max \left(t_{f, s}, t_{1}+T(z, f)\right)+T(f, z)<t_{2} \\
& c_{3}: T(z, f)+T(f, z) \leq k \\
& c_{4}: \min \left(t_{f, e}, t_{2}-T(f, z)\right)-\max \left(t_{f, s}, t_{1}+T(z, f)\right) \geq h
\end{aligned}
$$


where $k$ is a parameter denoting the maximum travel time an individual is willing to sacrifice for a round-trip from $z$ to $f$ and back to $z$, and $h$ is a parameter denoting the minimum activity time that is necessary to be able to enjoy a meaningful service at $f$.

In other words, a person at $z$ should be able to reach a facility $f$ within an opening hour interval $\left[t_{f, s}, t_{f, e}\right]\left(c_{1}\right)$ and return to $z$ within a time window from $t_{1}$ to $t_{2}\left(c_{2}\right)$. The two parameters $k$ and $m$ in conditions $c_{3}$ and $c_{4}$, respectively, incorporate some behavioral limitations of individuals: $k$ acknowledges that the time an individual is willing to travel is limited, while $h$ ensures that there should be sufficient time available within the considered time window to conduct an activity at $f$.

Based on these four conditions, we introduce two binary functions:

$$
\begin{aligned}
& B\left(z, t_{1}, t_{2}, f\right)=\left\{\begin{array}{l}
1 \text { if } z, t_{1}, t_{2}, f \mid \exists\left[t_{f, s}, t_{f, e}\right] \text { satisfying } c_{1}-c_{4} \\
0 \text { otherwise }
\end{array}\right. \\
& B\left(z, t_{1}, t_{2}, f,\left[t_{f, s}, t_{f, e}\right]\right)=\left\{\begin{array}{l}
1 \text { if } z, t_{1}, t_{2}, f,\left[t_{f, s}, t_{f, e}\right] \text { satisfying } c_{1}-c_{4} \\
0 \text { otherwise }
\end{array}\right.
\end{aligned}
$$

These binary functions are used to specify four spatiotemporal accessibility measures. The first measure reflects the ability to reach at least one facility in $F$ within the considered time window (able $=1$; unable $=0$ ) and is given by:

$S_{A B}\left(z, t_{1}, t_{2}\right)=\max _{f \in F} B\left(z, t_{1}, t_{2}, f\right)$

The second measure expresses accessibility in terms of the minimum travel time that is incurred by a person at location $z$ for a visit to $f$. Formally, this measure is given by:

$S_{T T}\left(z, t_{1}, t_{2}\right)=\min _{f \in F \mid B\left(z, t_{1}, t_{2}, f\right)=1}(T(z, f)+T(f, z))$

Third, accessibility can also be expressed as the spatial choice set available to a person within the considered time interval given various temporal limitations such as the opening hours associated with $F$. It is noted that this third measure forms the time-dependent equivalent of the cumulative opportunity measure with the travel time threshold depending on $k$, which is commonly employed in applied research (Wachs and Kumagai, 1973; Vickerman, 1974). The third measure is given by:

$S_{C S}\left(z, t_{1}, t_{2}\right)=\sum_{f} B\left(z, t_{1}, t_{2}, f\right)$

Finally, another component of accessibility is the degree to which spatiotemporal constraints imposed by the transportation and land-use system limit potential activity participation time. This component is measured by means of the maximum activity time that a person at $z$ would be able to spend at a service facility $f$ within the time window. Measuring the potential visitation time is important in light of the increased recognition of time and coordination problems in contemporary Western societies (see e.g. Moccia, 2000; Boulin, 2005; Deffner, 2005; Southerton and Tomlinson, 2005; Szollos, 2009). It also aligns with the emerging interest in time poverty issues in the social exclusion literature (see e.g. Kenyon et al., 2003; Lyons, 2003; Neutens 
et al., 2010b; Farber et al., 2011). This fourth measure of accessibility is formally given by:

$$
\begin{aligned}
& S_{A T}\left(z, t_{1}, t_{2}\right)=\max _{f}\left(\operatorname { m a x } _ { [ t _ { f , s } , t _ { f , e } ] \in R _ { f } } \left(\min \left(t_{f, e}, t_{2}-T(z, f)\right)-\max \left(t_{f, s}, t_{1}+\right.\right.\right. \\
& \left.T(z, f))) \cdot B\left(z, t_{1}, t_{2}, f,\left[t_{f, s}, t_{f, e}\right]\right)\right)
\end{aligned}
$$

The reader may notice that the measure of spatial choice (eq. 9) is to a certain degree an extension of the measure of ability (eq. 7). Nevertheless, it should be appreciated that including both measures is important since policymakers may want to capture and value both effects - ability and spatial choice - separately in the multicriteria analysis. The importance of distinguishing between both effects depends to a large extent on the type of services under consideration. Arguably, if services are uniform, such as those delivered by government offices (cf. section 3), the ability to reach just one service is more important than having spatial choice. Reversely, if services differ in many different qualities, such as public parks, spatial choice becomes a more important criterion.

\subsection{Spatiotemporal demand of services}

Having specified how well a zone is served by a set of service facilities within a considered time window, we now want to confront this level of service accessibility with the level of demand for services in the same zone. In this way, we can discover deprived areas as poorly served areas where the demand for services is high. Common practice is to use the residential population density $D_{\text {res }}(\mathrm{z})$ within a zone as a proxy of demand:

$$
D_{\text {res }}(z)=N_{\text {res }}(z) / A(z)
$$

where $N_{\text {res }}(z)$ and $A(z)$ denote the residential population size and area of zone $z$, respectively.

This measure of demand will also be used in the current study. However, in addition to this static measure, we will equally account for the time dimension of the use of places. More specifically, we will employ the area-weighted volume of trips of a particular purpose made to zone $z$ within the considered time window as a measure of demand. The idea is that by making allowance for the spatiotemporal dynamics of visitor populations, we can implicitly account for individuals' trip chaining behavior. For example, a zone with a low population density but a high number of jobs generates little demand from permanent inhabitants yet attracts a lot of workers who would be able to pay a visit to a service before or after work. This line of reasoning recognizes that the function of places are in a constant state of flux and that populations present in a zone show marked variations throughout the day and week (Parkes and Thrift, 1980; Janelle et al., 1998; Nuvolati, 2003; Zandvliet et al., 2008).

Since studies of space-time social ecology (Goodchild et al., 1993; Zandvliet et al., 2006) have shown that home-work differentiation comprises the strongest dimension of the urban space-time structure, followed by leisure and shopping, and education, these dimensions will be used in our study to measure the demand for services of 
day-time populations. Formally, the demand resulting from work $D_{W O R K}\left(z, t_{1}, t_{2}\right)$, leisure and shopping $D_{L E I S}\left(z, t_{1}, t_{2}\right)$, and education $D_{E D U}\left(z, t_{1}, t_{2}\right)$ are, respectively, given by:

$$
\begin{aligned}
& D_{\text {WORK }}\left(z, t_{1}, t_{2}\right)=\int_{t_{1}}^{t_{2}} N_{\text {WORK }}(z, t) d t / A(z) \\
& D_{\text {LEIS }}\left(z, t_{1}, t_{2}\right)=\int_{t_{1}}^{t_{2}} N_{L E I S}(z, t) d t / A(z) \\
& D_{E D U}\left(z, t_{1}, t_{2}\right)=\int_{t_{1}}^{t_{2}} N_{E D U}(z, t) d t / A(z)
\end{aligned}
$$

where $N_{\text {work }}(z, t), N_{\text {leis }}(z, t)$ and $N_{e d u}(z, t)$ denote the number of trips to work, leisure/shopping and education related activities, respectively.

\subsection{Confronting accessibility and demand}

In the previous subsections, we have identified eight relevant measures of service accessibility and service demand, four of each. The relative importance of these measures is assessed and synthesized through a GIS-based multi-criteria evaluation (MCE). Key in this evaluation is the assignment of weights to each criterion (i.e. measure of accessibility/demand). To date, an assortment of techniques has been proposed for developing these weights, with perhaps the most well-known and intuitively appealing method being the analytical hierarchy process (AHP) based on pairwise comparison on a ratio scale proposed by Saaty (1977). This method has gained acceptance in a wide range of research areas including urban planning (e.g. Jankowski, 1989), transportation (e.g. Rybarczyk and Wu, 2010), biology (e.g. Kangas and Kuusipalo, 1993) and geology (e.g. Dai et al., 2001). AHP enables to arrange the different criteria in a hierarchical order and assign numerical values to judgements of the user (e.g. policy makers) on their relative importance. This is done by means of a pairwise comparison matrix $M$ in which each criterion $m$ is rated against every other criterion as follows:

$M=\left[\begin{array}{ccc}w_{1} / w_{1} & \cdots & w_{1} / w_{n} \\ \vdots & \ddots & \vdots \\ w_{n} / w_{1} & \cdots & w_{n} / w_{n}\end{array}\right]$

where $w_{i}$ is the weight assigned to $m_{i}$ and $n$ is the number of criteria under consideration.

This matrix has positive entries $m_{i j}$ everywhere and satisfies the reciprocal property $m_{i j}=1 / m_{j i}$. In order to derive the priorities among the criteria in this matrix, ratings are made for each pairing on a nine-point scale. If a row criterion is more important than a column criterion, a rating between 2 (slightly more important) and 9 (extremely more important) is applied. Conversely, the rating varies between the reciprocals $1 / 2$ and $1 / 9$. When both criteria are equally important, the rating equals unity.

As a decision maker may not be able to express consistent preferences in case of several criteria, the consistency of a decision maker's entries in the pairwise comparison matrix should be verified. A common method for estimating priorities in $\mathrm{AHP}$ is the one based on the eigenvector of $M$. It has been shown that the 
normalized eigenvector corresponding to the largest eigenvalue of $M$ generates the relative weights $w_{i}$ of the criteria, with $\sum_{i} w_{i}=1$. These weights can be obtained from the following equation (Saaty, 1977, 1990):

$\left(M-\lambda_{\max } \cdot I\right) \cdot W=0$

where $\lambda_{\max }$ denotes the largest eigenvalue of $M$; $I$ denotes the unit matrix; and $W$ denotes the vector of weights reflecting the relative priorities of the criteria.

Based on this principal eigenvalue method, a consistency ratio can be calculated to determine the probability that the pairwise judgements were randomly generated. This ratio is given by:

$C R=C I / R I$

where $R I$ denotes the random index representing the average consistency of a randomly generated pairwise comparison matrix (as reported in Saaty (1980) for different orders $n$ of $M$ ); and $C I$ is the consistency index which can be calculated as:

$C I=\left(\lambda_{\max }-n\right) /(n-1)$

In other words, $C R$ indicates the degree to which individual ratings would have to be altered if they were to be perfectly consistent with the best fit weightings achieved. As a rule of thumb, it can be stated that if $C R$ is smaller than 0.1 , judgements are consistent and the derived weights are valid.

The derived weights are used to make a trade-off between the measures introduced in sections 2.1. and 2.2 through a weighted linear combination (WLC). Ultimately, the aim is to rank a finite number of alternative zones $\mathrm{z}$ in terms of service deprivation (i.e. poorly served zones with a high demand). Service deprivation in a zone within a time window is calculated as follows:

$V\left(z, t_{1}, t_{2}\right)=-w_{1} \cdot \tilde{S}_{A B}\left(z, t_{1}, t_{2}\right)+w_{2} \cdot \tilde{S}_{T T}\left(z, t_{1}, t_{2}\right)-w_{3} \cdot \tilde{S}_{C S}\left(z, t_{1}, t_{2}\right)-w_{4} \cdot$ $\tilde{S}_{A T}\left(z, t_{1}, t_{2}\right)+w_{5} \cdot \widetilde{D}_{R E S}(z)+w_{6} \cdot \widetilde{D}_{W O R K}\left(z, t_{1}, t_{2}\right)+w_{7} \cdot \widetilde{D}_{L E I S}\left(z, t_{1}, t_{2}\right)+w_{8} \cdot$ $\widetilde{D}_{E D U}\left(z, t_{1}, t_{2}\right)$

where $V\left(z, t_{1}, t_{2}\right)$ is termed the time-dependent service deprivation index.

Note that the criteria in eq. (19) are standardized - as indicated by the tilde - to make these commensurable for linear weighting. A positive sign is used for $\tilde{S}_{T T}\left(z, t_{1}, t_{2}\right)$, because longer travel yields more deprivation.

\section{Case study}

To illustrate the usefulness of the time-dependent service deprivation index outlined in the previous section, a case study is elaborated. The case study concerns an examination of spatiotemporal gaps in the service delivery of government offices in the city of Ghent (Belgium). These offices are responsible for the administration of citizens regarding marriage, cohabitation, birth, death, residential moves, travel, elections, etc. Based on the identification of service-deprived areas, an assessment 
is made of the suitability of potential locations and operating hours for a mobile government office bus. In the following subsections, we subsequently describe the background, study area, data, assumptions and parameters, and results.

\subsection{Background}

Ghent, together with many other cities, is increasingly facing the challenges brought forth by emerging cultural, demographic, economic, and technological developments in today's urban societies. One important development is the diversification of individual activity-travel patterns resulting from the expanded plurality of lifestyles and household structures within the city - including most notably the rise of dual-earner families - which has urged policy makers to rethink the ways in which urban structure should be organized, both spatially and temporally (Musterd and van Zelm, 2001; Bertolini and Dijst, 2003; Healey, 2004). Given that the increased plurality of lifestyles has been accompanied by a desynchronization and individualization of temporal rhythms within the city, a growing need arises to better attune the accessibility of urban services to the changed activities and travel patterns of urban citizens (Breedveld, 1998; Ritsema van Eck et al., 2005). Harmonization problems of this kind currently occur in Ghent, as is evidenced by a recent public opinion survey ${ }^{1}$ of the quality of public services within the city, which has articulated people's discomfort with the limited operating hours of accessible service. At the same time, however, cities such as Ghent are also increasingly confronted with reduced budgets and means to deal with these issues.

In response to the above developments, local authorities of Ghent have decided to start up the LEO project ('Loket En Onthaalbeleid' - Dutch for 'Office Window Services Policies') with the intention to come up with new ways to improve the accessibility of and provide user-oriented solutions to the delivery of public services. Part of the project aims at revising the spatial distribution of government offices and optimizing their number and historically grown hours of operation. To accommodate gaps in service provision, local authorities are planning to operate a mobile government office. At this point, policy makers and urban experts have already selected a number of potential stops on a very detailed level (e.g. near local shopping centers and major (public) transportation hubs) (Figure 1). The selection of these stops has been largely prompted by subjective considerations and practical requirements (e.g. well accessible land located away from main roads, access to electricity etc.). However, they wanted to know whether the location of these stops also matches the deprivation resulting from the imbalance between demand and (lack of) accessibility of services. It is against this background that the current study examines service deprivation to evaluate the suitability of alternative stops within the city.

\subsection{Study area}

Since the services supplied by the government offices are targeted strictly at the inhabitants of Ghent, it suffices to study the area circumscribed by the administrative border of Ghent. Ghent is the capital of the Belgian province of East Flanders. The

\footnotetext{
${ }^{1}$ The survey has been conducted by the consultancy office M.A.S. (Market Analysis \& Synthesis) at the end of 2007. More information about the survey can be found at www.gent.be. The mismatch between opening hours of public services and the working schedules of the active population in Belgium has been studied recently by Testaankoop (N. N., 2010).
} 
city is densely populated (1,506 inhabitants $\left./ \mathrm{km}^{2}\right)$ and approximately $156 \mathrm{~km}^{2}$ in size, with about 235,000 inhabitants. Ghent is a trading center on par with Hamburg (Germany) and Le Havre (France) and is characterized by an industrial concentration in the port zone in the northern part of the city. Figure 1 shows the study area with the spatial distribution of fifteen permanent government offices under scrutiny as well as the selected potential stops for a mobile office. In addition, Figure 2 shows the land-use pattern (Corine land cover, level 2) within the city, which may be helpful to the reader to get a feel of the study area and interpret the results in section 3.5.

\section{[insert Figure 1 here]}

[insert Figure 2 here]

\subsection{Data}

Four sources of data inform the analysis below. The first source concerns data about the transportation system and the permanent government offices. To represent the transportation system, a TeleAtlas ${ }^{\circledR}$ MultiNet $^{\mathrm{TM}}$ data set (version 2007.10) is employed. This dataset contains a detailed topological representation of the Belgian road network built up by links and nodes to which various attributes such as turn restrictions, speed limit, and functional road classification are attached. The second source of information about the government offices was obtained from the local authorities of Ghent. For this analysis, we have taken into account their exact geocoded locations and two sets of operating hours. The first set corresponds with the current operating hours. The second set represents a hypothetical scenario in which the offices no. 1, 2, 3, 4, 7, 10, and 13 in the more peripheral areas of the city have been closed (see Figure 1); the opening hours of the other offices have remained unaltered in this scenario. The suitability of the selected stops is investigated in both scenarios. No distinction between offices is made in terms of attractiveness, since the services they supply are generally uniform regarding civil affairs. The authors would like to emphasize that the hypothetical scenario of closures only serves the purpose of academic exercise - that is, it does not reflect an actual policy measure envisaged by local authorities.

The third source of information stems from census data of Ghent. This data set has been used to determine the measure of demand in eq. (11) (i.e. the residential population density per census ward). Figure 1 shows important spatial variations in population density across different parts of the city. The sparsely populated port zone in the north of Ghent is unmistakable relative to the high population densities in the city center.

Finally, to determine the measures of demand in eq. (12)-(14), we have used the origin-destination (OD) matrices of the Flanders Multimodal Model (MMM). The MMM is a macro-traffic model that has been developed since 1998 and is commissioned by the Flemish government. The OD matrices simulate trip volumes during a time window for various trip purposes. The model has been calibrated on the basis of the decennial census, traffic count data, and the OVG ('Onderzoek Verplaatsingsgedrag') travel diary data (see Verhetsel et al., 2007). The MMM is essentially composed of five sub-models, one for each province of Flanders, including the Brussels-Capital region for consistency(Boussauw et al., 2011). Every 
sub-model is represented by a GIS layer that divides the province into traffic analysis zones (TAZs). While in urban areas these TAZs correspond largely with the census wards, some repartitioning was necessary in the sparsely populated port area of Ghent to combine the MMM data with the residence population density data. In this study, the number of trip arrivals per ward simulated by the MMM model for the three considered trip purposes (i.e. employment, leisure, and education) was used as measure of demand. However, because it was computationally too intensive to calculate separate OD matrices per trip purpose for various times of the day for each day of the week, only a single simulation run of the travel volumes per trip purpose on an average weekday between $4 \mathrm{AM}$ and $11 \mathrm{AM}$ (i.e. morning traffic) has been made available to us. While this dataset does not enable us to account for temporal variations in the spatial pattern per trip purpose, we can adjust the relative importance of the different trip purposes over time. For example, we may increase the relative importance of leisure trips over work and school trips in the weekends by specifying two sets of weights $w_{i}$ in eq. (19) for the demand measures (see also further in section 3.4.). Of course, this assumption implies that zones which are more attractive for leisure relative to other zones on an average weekday morning are also more attractive relative to other zones during weekends; but at least we can control for the most significant part of temporal variation in the relative importance of trip purposes.

\subsection{Assumptions and parameters}

Using the geocoded locations of government offices and the transportation network data, we have estimated the travel times necessary for the calculations of the four measures of accessibility (eq. 7-10) within ESRI ${ }^{\circledR}$ 's ArcGIS ${ }^{\mathrm{TM}}$ Network Analyst (9.3.1). For the current study, we have only considered travel times by car; the incorporation of other travel modes such as bicycle or public transportation is left for future research. Depending on the road class and the time of day during which travel takes place, different congestion factors have been applied (Table 1). This congestion factor has been derived from average travel times recently reported by Maerivoet and Yperman (2008) under the authority of the Federal Government Service for Mobility and Transport. The travel time between two point locations has been calculated by means of a shortest path algorithm after weighting the travel times per network arc by their road class and time-of-day dependent congestion factors. The calculation of travel times between a zone and a service facility has been done in two steps. First, we have computed the travel times between the considered service facility from/to all links of the transportation network within the zone rather than from/to only a single characteristic point (e.g. centroid) of the zone. Second, the travel times from/to all links have been averaged and weighted according to their total length within the considered zone. These weighted averages have been used as proxy for $T(z, f)$ and $T(f, z)$. In this way, we can to a certain extent control for the spatial variation of travel times within a zone.

\section{[insert Table 1 here]}

In consultation with local policy makers, the parameters $k$ and $h$, denoting the travel time threshold and minimum required activity duration, have been set at 15 and 20 minutes, respectively. Using these parameters, we have calculated the measures of service accessibility for each census ward. The relative importance of the eight criteria specified in section 2.1. and 2.3. has been determined in dialogue with local 
policy makers using a pairwise comparison matrix. Table 2 shows the ratings that have been applied for the current analysis. As explained earlier, for each pairing, separate ratings have been specified for weekdays (light grey) and weekends (dark grey). Because of symmetry, only the upper triangular half of the matrix has to be completed (the remaining cells are simply the reciprocals of the upper triangular half). Satisfactory consistency ratios $(C R<0.1)$ are obtained for both sets of ratings $\left(C R_{\text {weekday }}=1 \% ; C R_{\text {weekend }}=4 \%\right)$. As can be read from the table, the ability to access a government office and the residential population density have been identified as most important criteria on both weekdays and weekends. In other words, mobile offices are preferentially located in residential neighborhoods that have no or little access to permanent offices, given the considered assumptions and parameters. Travel time, spatial choice, and possible activity time, on the other hand, are valued equally yet less important compared to ability and residential population. Finally, it was assumed that neighborhoods which are attractive for leisure activities are more important during weekends than on weekdays. Using the principal eigenvalue method (see section 2.3), the vectors of numerical weights corresponding to these ratings have been computed for weekdays and weekends separately (Table 2). These weights serve to calculate the time-dependent service deprivation index as the weighted linear combination in eq. (19).

[insert Table 2 here]

\subsection{Results}

This results section has an illustrative purpose. It will use two different time intervals to demonstrate that the proposed accessibility measures can capture temporal changes in the spatial pattern of accessibility (section 3.5.1.); the ways in which accessibility interacts with spatial demand to create deprivation (section 3.5.2.); and the impact of closures on spatial variation in deprivation (section 3.5.3.). The selected time intervals are Monday morning and Saturday morning, both between 9 AM and 10 AM. Although the deprivation index can be calculated for any time interval during the week, these two intervals have been specifically chosen because they are expected to yield sharp contrasts in deprivation and accessibility (and thus best illustrate temporal differences) given the existing differences in opening hours, congestion, and activities within the city between weekdays and weekends.

\subsubsection{Time-dependent accessibility measures}

A first essential step in the analysis of service deprivation consists of calculating the four time-dependent accessibility measures. Figures 3 (a-d) and (e-h) depict the spatial variation in these measures on Monday morning and Saturday morning, respectively. The measures have been displayed per link of the transportation network to obtain as much detail as possible in the resulting accessibility patterns. Figure 3a shows that on Monday the majority of transportation links in the city can be accessed within the governing constraints between $9 \mathrm{AM}$ and $10 \mathrm{AM}$ (i.e. opening hours, performance of the transportation network) and the requirements set by the local authorities (i.e. maximum travel time, minimum activity participation time). The offices cannot be reached, however, from more peripheral parts in the city such as 
the northern port area and the southwestern corner of the city, where the land use mainly consists of urban fabric, agricultural areas and pastures (Figure 2). While the inability to access an office from the northern area can be largely attributed to the fact that none of the northern offices (1,2 and 3) operates on Monday morning, the poor access in the southwestern corner is simply a consequence of the lack of office locations in the surroundings. Remarkably, there is also a small area in the center of the city that remains unserved on Monday morning, despite the availability of the nearby office 15 , which is opened during the entire considered time interval. A closer inspection of the transportation network reveals that, from an accessibility point of view, office 15 least effectively serves its northwestern neighborhoods because of several barriers including, in particular, waterways and one-way streets.

The locations from which to access an office on Saturday morning are much more restricted relative to Monday morning because only office 15 then operates (Figure $3 e)$. However, some locations within the city center which were unserved on Monday are now being served due to lower congestion factors on the weekend. Nevertheless, Figure 3e shows that the catchment area of office 15 still extends predominantly in south-southeastern directions, especially along the important highways.

Next, we can also differentiate space in terms of spatial choice. Figure $3 b$ shows that spatial choice on Monday is particularly high around office 8 where more than four offices can be reached during the time interval. Figure $3 f$, on the other hand, does not exhibit variation in spatial choice since only 1 office is accessible on Saturday.

Another important component of accessibility is spatial proximity. The values for this component are high at locations where the shortest path along the transportation network to an accessible (open) office is small. On Monday high values for spatial proximity are encountered around all but the three northern offices (1,2 and 3); while on Saturday proximity values are highest southeast of office 15.

Finally, attention has also been paid to the amount of time to visit a government office (Figure $3 d$ and $h$ ). While the spatial variation in potential visitation time corresponds largely with the spatial variation in travel time to the closest office, both on Monday and Saturday morning, it should be noted that this is not necessarily the case for other time intervals during the week. Differences in spatial variations of these components are likely to occur whenever locations can be found for which the closest office differs from the office where a person can stay the longest. This occurs, for example, on Wednesday when offices 1, 2, and 3 in the north of Ghent are opened, each during different time intervals. However, given that the opening hours of the majority of government offices largely run parallel to each other, the occurrence of such cases on other days of the week is rather rare in this specific case study.

[Insert Figure 3a-d here, next to each other for comparison] [Insert Figure 3e-h here, next to each other for comparison]

\subsubsection{Time-dependent deprivation index}

The above differences in accessibility have been confronted with the time-dependent measures of demand using a GIS-based multi-criteria analysis. Figure 4 depicts the 
spatial distribution of the deprivation index on Monday morning. The index has been categorized using Jenks' natural breaks classification (Jenks and Caspall, 1971). At least three spatial trends can be observed. First, the northern part of the study area containing the potential stops $A, B$ and $D$ is, after confrontation with the criteria of demand, identified as being a deprived area, despite its low population density (see Figure 1) and the relatively low number of work/leisure/education activities in this area on Monday morning. Second, two major areas in the southwest corner of the study area, near stops $\mathrm{J}$ and $\mathrm{K}$, are also seen as deprived. All zones in this area have poor (if any) access to services, but many have a higher population density and more activity on Monday morning (and thus a higher deprivation index)) compared to the deprived zones in the northern area. Third, the deprivation index is also high in some specific neighborhoods in the city center itself. These neighborhoods, such as the socalled $19^{\text {th }}$ century urban belt around stop $G$, are characterized by an extremely high demand due to peaking levels of population density and activities, whilst travel time to the closest office can be relatively high and the number of accessible offices moderate.

Figure $4 \mathrm{~b}$ depicts the spatial variation in deprivation index on Saturday. The index appears to be highest in the area around stop G, while, in contrast to Monday morning, the zones in the northern and southwestern parts of the study area are now seen as relatively less deprived relative to other zones. The majority of the least deprived zones are located southwest of office 15.

Taken together, if local authorities would like to operate the mobile government office bus on a Monday morning, we would advise to use either stop $\mathrm{J}$ in the southwestern area or stop $A$ in the northern area, since the zones containing these stops yield the highest index in each of both areas with $V_{J}=0.29$ and $V_{A}=0.27$. If they want to operate the bus on Saturday morning while office 15 is open, we would recommend not to supply mobile services at the stops in the relatively sparsely populated areas north and southwest of the study area, but rather at stop $\mathrm{G}\left(V_{G}=0.37\right)$ in the city center. This stop can attract both local residents and visitors that can integrate a service visit into a chain with other activities such as leisure and shopping, while the area surrounding $\mathrm{G}$ is only moderately served by office 15 through the transportation network.

[Insert Figure 4a here]

[Insert Figure $4 b$ here]

\subsubsection{Spatial difference in deprivation after closures}

A final type of comparison can be made between service deprivation before and after closures of the peripheral offices. Since these closures do not affect the spatiotemporal accessibility of services on Saturday, the spatial pattern of deprivation after closures will be equal to the one portrayed in Figure 4b. On Monday, however, the spatial pattern does change and is represented in Figure 5. Overall, the zones in the vicinity of offices 7,2 , and 10 are impacted most strongly by the closures, resulting in two clearly identifiable areas with high deprivation north and southwest of the study area. Further there are also some zones with a high level of deprivation in 
the densely populated area surrounding G. Noticeably, the area around closed office 4 is still relatively well served, as are many zones around the opened offices $12,6,14$, 5,11 , and 9 .

To gain more insight into the (mis)match between accessibility and demand in a zone, we have decomposed the scores for the different criteria in a radar diagram in Figure 6. For illustrative purposes, this has been done for the zones of three different stops $(\mathrm{J}, \mathrm{G}, \mathrm{H})$ with a diverse radar pattern. The diagram shows the scores per criterion relative to the maximum value over all the stop zones. In this way, the scores for the different stop alternatives can be easily compared relative to one another. For example, stop $\mathrm{H}$ is located in a stop zone with the largest number of work, leisure, and education activities on Monday morning and thus the scores for these criteria equal 1. The population density, on the other hand, is largest in the zone containing stop G. This stop zone has a moderate level of work/leisure/education activities, is rather deprived in terms of spatial choice but has a high level of proximity and activity participation time. Zone $\mathrm{J}$ is maximally deprived along all the four different accessibility measures but generates only little demand. None of the three investigated stop zones, however, exhibits high demand with low accessibility or low demand with high accessibility. This is also true for the other stop zones that were analyzed in the same manner. This means that even after closures, zones with a high demand are still well supplied with government services. Zones with a low demand that have been severely affected by the closures of permanent offices, such as $\mathrm{J}, \mathrm{K}$, $A, B$ and $C$, should then preferentially be served by the mobile office.

\section{[Insert Figure 5 here]}

[Insert Figure 6 here]

\section{Conclusion}

Designating underserved neighborhoods using GIS has been deemed important in shaping policies aimed at enhancing social inclusion and ensuring equitable access. However, the focus of methodological approaches to identify socio-spatial accessibility inequalities abounding in the relevant literature has been predominantly on the shortcomings in the spatial coverage of the transportation system and the urban opportunity landscape, whereas temporal variations in accessibility due to opening hours and congestion are more often than not left unconsidered. The neglect of temporal variation is also present on the demand side that in empirical work has generally been modeled using the spatial distribution of the stationary resident population across street addresses or zones.

Recognizing this limitation, this paper has suggested to measure accessibility to services at a location or zone per time interval. The proposed accessibility measures have been confronted with not only the stationary resident population but also the level of activity of different visitor populations using a GIS-based multi-criteria analysis. The method enables to identify spatiotemporal rather than merely spatial differences in service deprivation. The applicability of the method has been illustrated in a case study about the planning of a mobile government office bus in the city of Ghent. It has been shown that the suitability of alternative stop locations for the bus depends on the time interval during which it will be operated. 
While the current paper has revealed spatial deprivation patterns in only two different time intervals using a fixed set of parameters (before and after closures), a multitude of scenarios with other parameters and at other times of the week may be developed in further research. From the perspective of sustainable transportation, one potentially interesting scenario would be to consider the spatiotemporal variations in deprivation under the assumption of non-motorized travel modes or public transportation. Another avenue would be to target the analysis to certain vulnerable or relatively immobile groups in society such as the elderly or young households with dependent children and lacking access to a car. Finally, one may also undertake a more systematic evaluation of the suitability of stops at different time intervals during the week in order to determine an optimal timetabling of the mobile service bus.

Despite the many empirical refinements to be made in future research, this study has offered a methodological framework that may help to improve or complement the static indicators that are currently employed in various policy relevant documents in Belgium and elsewhere.

\section{References}

Bertolini, L. and Dijst, M., (2003). Mobility environments and network cities. Journal of Urban Design 8, 27-43.

Boulin, J. Y., (2005). Is the societal dialogue at the local level the future of social dialogue? Transfer: European Review of Labour and Research 11(1), 439-448.

Boussauw, K., Neutens, T. and Witlox, F., (2011). Minimum commuting distance as a spatial characteristic in a non-monocentric urban system: The case of Flanders. Papers in Regional Science 90(1), 47-66.

Breedveld, K., (1998). The double myth of flexibilization - Trends in scattered work hours, and differences in time-sovereignty. Time \& Society 7(1), 129-143.

Casas, I., (2007). Social exclusion and the disabled: An accessibility approach. Professional Geographer 59(4), 463-477.

Casas, I., Horner, M. W. and Weber, J., (2009). A comparison of three methods for identifying transport-based exclusion: A case study of children's access to urban opportunities in Erie and Niagara Counties, New York. International Journal of Sustainable Transportation 3, 227-245.

Church, R. L. and Marston, J. R., (2003). Measuring accessibility for people with a disability. Geographical Analysis 35(1), 83-96.

Comber, A., Brunsdon, C. and Green, E., (2008). Using a GIS-based network analysis to determine urban greenspace accessibility for different ethnic and religious groups. Landscape and Urban Planning 86(1), 103-114.

Dai, F. C., Lee, C. F. and Zhang, X. H., (2001). GIS-based geo-environmental evaluation for urban land-use planning: a case study. Engineering Geology 61(4), 257-271.

Deffner, A. M., (2005). The combination of cultural and time planning. City 9(1), 125141.

Delafontaine, M., Neutens, T., Schwanen, T. and Van de Weghe, N., (2011). The impact of opening hours on the equity of individual space-time accessibility. Computers, Environment and Urban Systems 35(4), 276-288. 
Farber, S., Paez, A., Mercado, R. G., Roorda, M. and Morency, C., (2011). A timeuse investigation of shopping participation in three Canadian cities: Is there evidence of social exclusion? Transportation 38(1), 17-44.

Goodchild, M. F., Klinkenberg, B. and Janelle, D. G., (1993). A factorial model of aggregate spatiotemporal behavior: Application to the diurnal cycle. Geographical Analysis 25(4), 277-294.

Healey, P., (2004). The treatment of space and place in the new strategic spatial planning in Europe. International Journal of Urban and Regional Research 28(1), 45-67.

Janelle, D. G., Klinkenberg, B. and Goodchild, M. F., (1998). The temporal ordering of urban space and daily activity patterns for population role groups. Geographical Systems 5(5), 117-137.

Jankowski, P., (1989). Mixed-data multicriteria evaluation for regional planning: A systematic approach to the decision making process. Environment and Planning A 21(3), 349-362.

Jenks, G. F. and Caspall, F. C., (1971). Error on choroplethic maps: Definition, measurement, reduction. Annals of the Association of American Geographers 61(2), 217-244.

Kangas, J. and Kuusipalo, J., (1993). Integrating biodiversity into forest management planning and decision-making. Forest Ecology and Management 61(1-2), 1-15.

Kenyon, S., Rafferty, J. and Lyons, G., (2003). Social exclusion and transport in the UK: A role for virtual accessibility in the alleviation of mobility-related social exclusion? Journal of Social Policy 32, 317-338.

Kwan, M. P., (1998). Space-time and integral measures of individual accessibility: A comparative analysis using a point-based framework. Geographical Analysis 30(3), 191-216.

Kwan, M. P. and Weber, J., (2008). Scale and accessibility: Implications for the analysis of land use-travel interaction. Applied Geography 28(2), 110-123.

Langford, M. and Higgs, G., (2010). Accessibility and public service provision: evaluating the impacts of the Post Office Network Change Programme in the UK. Transactions of the Institute of British Geographers 35(4), 585-601.

Lucas, K., (2006). Providing transport for social inclusion within a framework for environmental justice in the UK. Transportation Research Part a-Policy and Practice 40(10), 801-809.

Lucas, K., Tyler, S. and Christodoulou, G., (2009). Assessing the 'value' of new transport initiatives in deprived neighbourhoods in the UK. Transport Policy 16(3), 115-122.

Lyons, G., (2003). The introduction of social exclusion into the field of travel behaviour. Transport Policy 10(4), 339-342.

Maerivoet, S. and Yperman, I., (2008) Analyse van de verkeerscongestie in België rapport in opdracht van Federale Overheidsdienst Mobiliteit en Vervoer, Transport \& Mobility Leuven.

Miller, H. J., (2007). Place-based versus people-based geographic information science. Geography Compass 1(3), 503-535.

Moccia, F. D., (2000). Planning time: An emergent European practice. European Planning Studies 8(3), 367-375.

Musterd, S. and van Zelm, I., (2001). Polycentricity, households and the identity of places. Urban Studies 38(4), 679-696.

N. N., (2010). Gemeenten: Soms dure informatie. Testaankoop 545, 12-17. 
Neutens, T., Schwanen, T. and Witlox, F., (2011). The prism of everyday life: Towards a new research agenda for time geography. Transport Reviews 31(1), 25-47.

Neutens, T., Schwanen, T., Witlox, F. and De Maeyer, P., (2010a). Equity of urban service delivery: a comparison of different accessibility measures. Environment and Planning A 42(7), 1613-1635.

Neutens, T., Schwanen, T., Witlox, F. and De Maeyer, P., (2010b). Evaluating the temporal organization of public service provision using space-time accessibility analysis. Urban Geography 31(8), 1039-1064.

Neutens, T., Versichele, M. and Schwanen, T., (2010c). Arranging place and time: A GIS toolkit to assess person-based accessibility of urban opportunities. Applied Geography 30(4), 561-575.

Nuvolati, G., (2003). Resident and non-resident populations: quality of life, mobility and time policies. Journal of Regional Science Analysis and Policy 33(2), 6783.

Omer, I., (2006). Evaluating accessibility using house-level data: A spatial equity perspective. Computers Environment and Urban Systems 30(3), 254-274.

Parkes, D. and Thrift, N., (1980). Times, Spaces and Places: A Chronogeographic Perspective. John Wiley and Sons, Chichester.

Preston, J. and Raje, F., (2007). Accessibility, mobility and transport-related social exclusion. Journal of Transport Geography 15(3), 151-160.

Ritsema van Eck, J., Burghouwt, G. and Dijst, M., (2005). Life styles, spatial configurations and quality of life in daily travel: an explorative simulation study. Journal of Transport Geography 13, 123-134.

Rybarczyk, G. and Wu, C. S., (2010). Bicycle facility planning using GIS and multicriteria decision analysis. Applied Geography 30(2), 282-293.

Saaty, T. L., (1977). A scaling method for priorities in hierarchical structures. Journal of Mathemmatical Psychology 15(1), 234-281.

Saaty, T. L., (1980). The analytical hierarchy process. McGraw Hill, New York.

Saaty, T. L., (1990). How to make a decision: The analytical hierarchy process. European Journal of Operational Research 49(1), 9-26.

Scott, D. M. and Horner, M. W., (2008). Examining the role of urban form in shaping people's accessibility to opportunities: An exploratory spatial data analysis. Journal of Transport and Land Use 1(2), 89-119.

Southerton, D. and Tomlinson, M., (2005). 'Pressed for time' - the differential impacts of a 'time squeeze'. Sociological Review 53(2), 215-239.

Szollos, A., (2009). Toward a psychology of chronic time pressure Conceptual and methodological review. Time \& Society 18(2-3), 332-350.

Talen, E. and Anselin, L., (1998). Assessing spatial equity: an evaluation of measures of accessibility to public playgrounds. Environment and Planning $A$ 30(4), 595-613.

Tsou, K. W., Hung, Y. T. and Chang, Y. L., (2005). An accessibility-based integrated measure of relative spatial equity in urban public facilities. Cities 22(6), 424435.

Turner, J. and Grieco, M., (2000). The impact of transport investment projects upon the inner city: a literature review. Time and Society 9(1), 129-136.

Verhetsel, A., Thomas, I., Van Hecke, E. and Beelen, M., (2007) Pendel in België. Deel I: Woon-Werkverplaatsingen, Federal Public Service Economy. 
Vickerman, R. W., (1974). Accessibility, attraction, and potential: a review of some concepts and their use in determining mobility. Environment and Planning $A$ 6(6), 675-691.

Wachs, M. and Kumagai, T. G., (1973). Physical accessibility as a social indicator. Socio-Economic Planning Sciences 7(5), 437-456.

Zandvliet, R., Bertolini, L. and Dijst, M., (2008). Towards Planning for a Mobile Society: Mobile and Residential Populations and the Performance of Places. European Planning Studies 16(10), 1459-1472.

Zandvliet, R., Dijst, M. and Bertolini, L., (2006). Destination choice and the identity of places: A disaggregated analysis for different types of visitor population environment in the Netherlands. Journal of Transport Geography 14(6), 451462. 


\section{TABLES}

Table 1. Congestion factor according to time of day, day of the week and road class.

Table 2. Pairwise comparison matrix. 


\section{FIGURES}

Figure 1. Distribution of government offices and population within the city of Ghent.

Figure 2. Land use within the city of Ghent.

Figure 3. Accessibility on Monday (a-d) and Saturday (e-h) between 9 AM and 10 AM: ability to access a government office (a and $e$ ); number of accessible offices (b and f); round-trip travel time (c and g); and activity participation time ( $d$ and $h$ ).

Figure 4. Spatial variation in deprivation index on Monday 9 AM - 10 AM (a) and Saturday $9 \mathrm{AM}-10 \mathrm{AM}(\mathrm{b})$.

Figure 5. Spatial variation in deprivation index on Monday 9 AM - 10 AM after closures.

Figure 6. Decomposition of deprivation index into different criteria of accessibility and demand. 